\title{
Penerapan Algoritma AES pada Dokumen Penting yang Disisipkan Dalam Citra Berbasis Algoritma LSB dan Sobel
}

\author{
Yunita Dwi Setiyaningrum ${ }^{1}$, Wijanarto ${ }^{2}$, Asih Rohmani ${ }^{3}$ \\ Fakultas Ilmu Komputer Universitas Dian Nuswantoro \\ Jl.Imam Bonjol No. 207 Semarang, Telp. (024) 3575916 \\ email : ${ }^{1}$ yunitadwisetiyaningrum@gmail.com, ${ }^{2}$ wijanarto@dsn.dinus.ac.id,
}

Diterima: 21 Oktober 2019; Direvisi: 22 Nopember 2019; Disetujui: 25 Nopember 2019

\begin{abstract}
Abstrak
Kemajuan teknologi berimbas pada kegiatan sehari-hari, misalnya sekarang ini masyarakat mudah mengirim dan menerima dokumen melalui e-mail tanpa terbatas oleh waktu dan jarak. Perkembangan teknologi ini juga berimbas pada peningkatan dampak negatif yang merugikan, seperti munculnya cybercrime, pishing, trojan, hackers. Penelitian ini bertujuan untuk meningkatkan pengamanan data pada dokumen penting yang tersimpan di server maupun sistem lain yang terdapat di PT Nasmoco Majapahit sebagai obyek penelitian. Metode yang dipakai adalah dengan menerapkan teknik kriptografi Advanced Encryption Standard (AES) pada dokumen yang akan disisipkan dalam citra dengan algoritma Least Significant Bit (LSB) dengan deteksi tepi Sobel. Teknik ini diharapkan mampu merahasiakan atau mengamankan dokumen penting milik perusahaan yang disisipkan dalam gambar, sedemikian sehingga gambar asli dengan gambar yang telah disisipi oleh dokumen penting tersebut menjadi sulit dibedakan oleh mata normal manusia pada umumnya. Hasil yang diperoleh dari penelitian ini menunjukkan bahwa algoritma AES dapat melakukan proses enkripsi dengan cukup cepat, yaitu rata-rata durasi sebesar 37,0976 detik. Pada deteksi tepi dalam proses penyisipan pesan bergantung pada objek dalam citra bukan hanya ukuran piksel saja semakin objek rumit maka semakin banyak koordinat yang digunakan untuk menyisipkan teks. Dan hasil kualitas citra stego setelah dilakukan pengujian menggunakan PSNR dan MSE hasil rata-ratanya juga cukup tinggi yaitu MSE sebesar 0,0425 dan PSNR sebesar 62,9392.
\end{abstract}

Kata kunci: kriptografi, dokumen, steganografi, citra

\begin{abstract}
Advances in technology have an impact on daily activities, for example now people can easily send and receive documents via email without being limited by time and distance. The development of this technology also has an impact on the increase of adverse negatives, such as preventing cybercrime, pishing, trojans, hackers. This research is aimed at increasing the security of data on important documents stored on servers or other systems in PT Nasmoco Majapahit as research objects. The method used is to apply cryptographic techniques Advanced Encryption Standard (AES) on documents that will be distributed in the image with the Least Significant Bit (LSB) algorithm with Sobel edge detection. This technique is expected to produce better or make important company documents that are inserted in the image, arranging the original image with an image that has been inserted by this important document becomes difficult to distinguish by the eyes of normal humans in general. The results obtained from this study indicate that AES can perform the encryption process quite quickly, namely an average duration of 37.0976 seconds. On edge detection in the process of inserting the message required on the object in the picture not only the size of the image. The more complicated objects, the more coordinates are used to insert text. And the results of the stego image quality after testing
\end{abstract}


using PSNR and MSE, the results of the assessment are also quite high, namely MSE of 0.0425 and PSNR of 62.9392.

Keywords: cryptography, documents, steganography, image

\section{PENDAHULUAN}

Berdasar hasil survei, pada periode 2000-2017 pertumbuhan jumlah pengguna internet di dunia mencapai 97.64\%. Dari prosentase pertumbuhan pengguna internet tersebut, Asia memperoleh predikat sebagai pengguna internet terbanyak di dunia dengan angka 49,7\% dan negara Indonesia mencapai 50,4\% [1]. Berdasarkan hasil survei diatas, adanya perkembangan teknologi yang serba canggih ini menyebabkan semakin bertambah pula cybercrime, salah satunya adalah pishing [2]. Masyarakat Indonesia harus dapat bertindak lebih cerdas dan selalu waspada dalam menyikapi munculnya teknologi yang semakin berkembang ini. Selain itu, keamanan data terutama dokumen rahasia juga menjadi hal utama yang harus di prioritaskan supaya bisa menghindari adanya kerentanan pencurian data rahasia. Di Indonesia, salah satu bentuk sasaran para pelaku cybercrime adalah pishing. Hal ini dibuktikan dengan hasil survei yang tercantum di Data dan Statistik Kementerian Komunikasi dan Informatika RI pada tahun 2014 mencapai 3,6\% [3]. Pishing bukan hanya terjadi di Indonesia saja, menurut thehackernews.com, maraknya pishing justru dengan mengatasnamakan orang yang dikenal oleh korban, agar mudah untuk melakukan penyusupan dokumen yang dikirim. Pada PT. Nasmoco, belum terdapat sistem untuk pengamanan saat mengirim dokumen penting melalui email. Oleh karena itu, dokumen yang bersifat rahasia ini harus dijaga keamanannya agar terhindar dari ancaman pihak luar.

Menurut Pasal 1 ayat (2) UU No.8 Tahun 1997 yang dimaksud dari dokumen penting perusahaan yaitu catatan, data, atau keterangan yang dibuat maupun diterima oleh perusahaan untuk pelaksanaan kegiatan diperusahaan tersebut, baik tertulis maupun dengan media apapun[4]. Beberapa penelitian terkait sudah dilakukan, di bidang enkripsi data dengan teknik kriptografi perbandingan kecepatan algoritma Advanced Encryption Standard (AES) dan Data Encryption Standard (DES), menghasilkan kesimpulan bahwa AES lebih cepat performanya yaitu 8,105 (windows) dan 7,11 (MAC) dibanding DES dari waktu eksekusi pada windows dan MAC [5].

Analisa performa algoritma LSB, DCT, dan DWT untuk aplikasi Digital Watermarking dengan Steganography, menghasilkan kesimpulan bahwa DCT mempunyai PSNR yang paling tinggi, sedangkan DWT mempunyai MSE yang lebih tinggi [6]. Sementara penelitian untuk meningkatkan nilai imperceptibility dari penampung teks dalam [7] menghasilkan penelitian untuk membandingkan lima algoritma deteksi tepi ini (Robert, Laplace, Prewitt, Sobel, Canny), bahwa deteksi tepi Canny mempunyai kualitas yang paling tinggi dengan nilai PSNR yang paling rendah dan nilai MSE yang paling tinggi. Namun, deteksi tepi sobel merupakan metode yang bisa dikatakan seimbang, dimana kapasitasnya tinggi namun nilai PSNR dan MSE tidak terlalu rendah dibanding deteksi tepi yang lain.

Sementara dalam [8] mencoba menganalisis kualitas dari citra stego (citra setelah disisipkan) dengan LSB dan AES dan hasilnya mengalami perubahan. Ini terbukti melalui hasil analisis histogram warna mulai dari citra asli ke citra hasil stego. Perubahan kualitas ini bergantung dari ukuran pesan yang disisipkan. Selain itu, citra berubah setelah proses penyisipan pesan. Dengan ketiga algoritma tersebut maka orang awam sulit membedakan gambar asli dengan gambar yang telah disisipi oleh pesan rahasia. Pada penelitian ini citra cover menggunakan format bitmap (*.bmp) yaitu salah satu jenis format file penyimpanan yang masih asli belum melalui proses kompresi yang berfungsi sebagai penyimpanan dari citra biner sampai citra berwarna. Terakhir, implementasi kriptografi CBC dan steganografi LSB menggunakan deteksi tepi Sobel yang dilakukan dalam [9], pada citra stego yaitu dengan melihat dari hasil PSNR yang tinggi dan nilai MSE yang rendah maka kualitas citra tersebut semakin bagus . 


\section{METODE PENELITIAN}

Data yang digunakan pada penelitian adalah file dokumen berformat *.docx yang disisipkan pada citra berformat *.bmp. Gambar 1 menjelaskan skema penelitian, yang dimulai dari proses mengumpulkan dokumen berformat *.docx dengan besar file maksimal $50 \mathrm{~Kb}$.

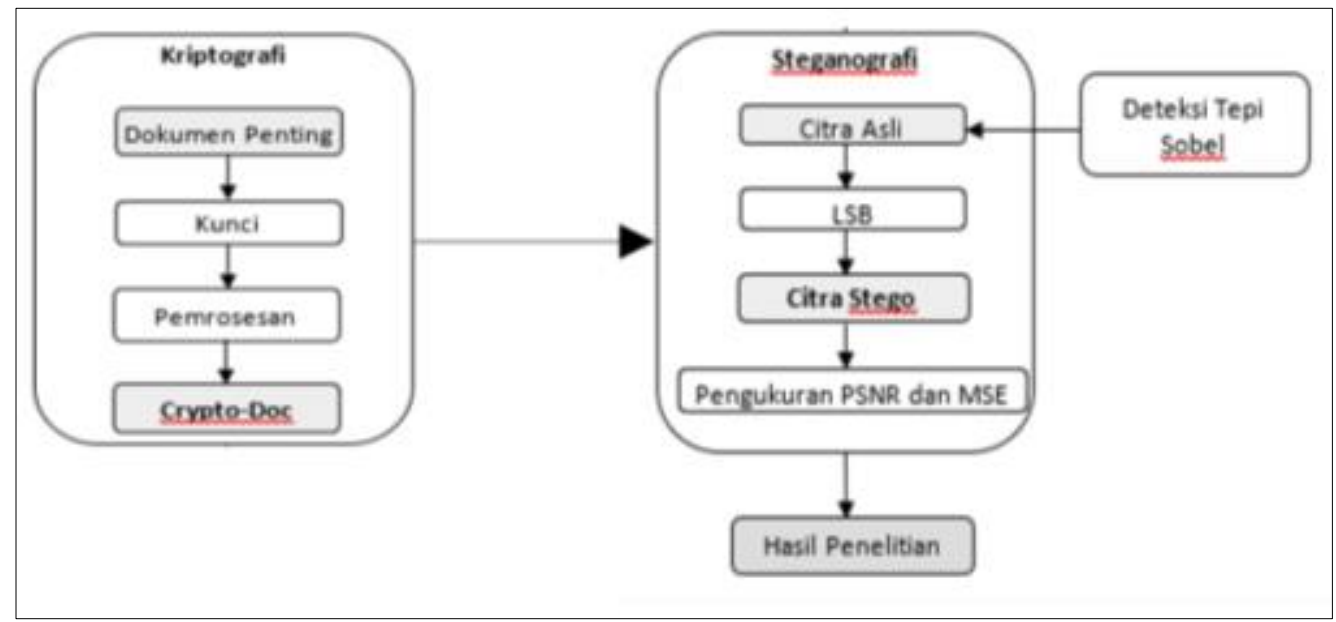

Gambar 1. Skema Penelitian

Setelah itu disiapkan pula citra yang sudah ditentukan sebagai media untuk penyisipan dari dokumen tersebut, dengan kompresi bmp pada dimensi 256 x 256, 512 x 512, dan 1024 x 1024 piksel. Langkah selanjutnya adalah melakukan proses enkripsi dan dekripsi dari sample dokumen secara manual, sehingga menghasilkan kripto dokumen (dokumen yang sudah terenkripsi isinya), dengan langkah-langkah seperti dijelaskan pada gambar 2.

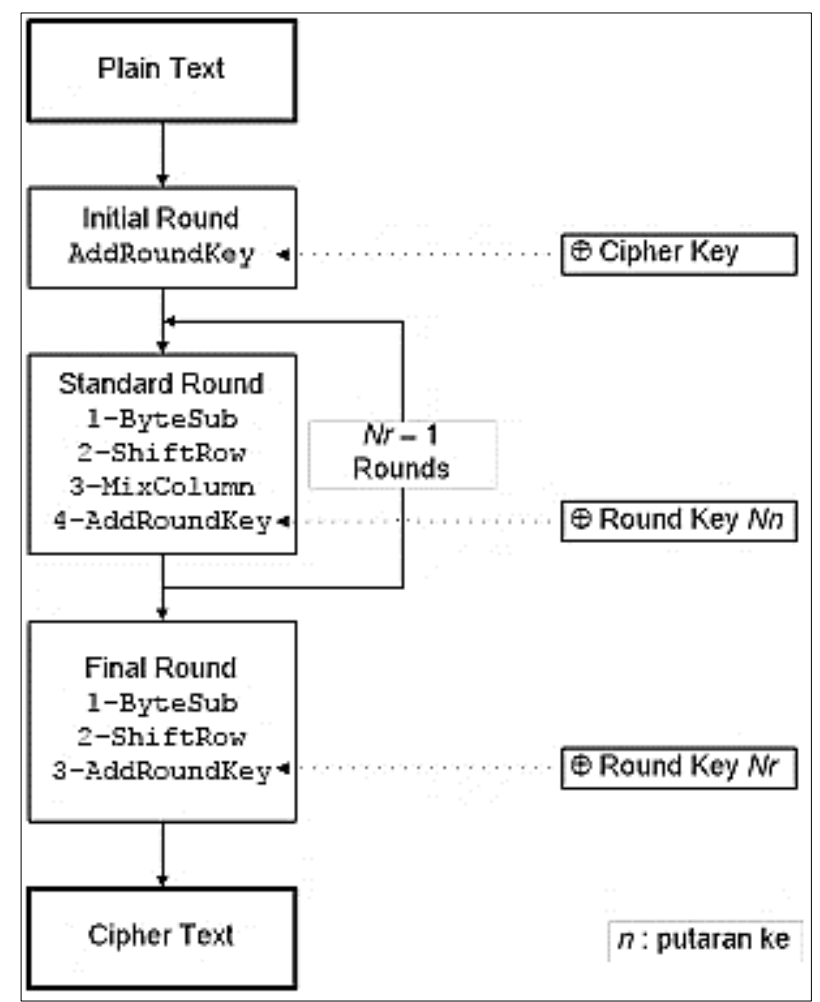

Gambar 2. Skema Algoritma AES 
Dari dokumen terenkripsi akan dilakukan initial round dengan menambahkan chiper key sehingga akan menghasilkan data untuk dilakukan standard round sebanyak $\mathrm{N}$ putaran, mulai dari membagi byte (byte sub), operasi menggeser baris (shift row), mencampur kolom (mix coloumn) dan menambahkan round key yang diproduksi dengan operasi XOR Round Key setiap putarannya. Setelah itu finalisasi putaran dengan melakukan proses terhadap byte sub, shift row dan menambah ulang round key ke-N dan hasil akhirnya berupa chipertext.

Langkah berikutnya, dilakukan penyisipan data kripto dokumen tersebut ke dalam citra (dengan kompresi citra yang digunakan berformat*.bmp dengan ukuran 1024 x 1024 piksel) dengan menggunakan metode LSB hingga mendapatkan hasil citra stego, seperti pada skema gambar 3 dibawah ini [10]

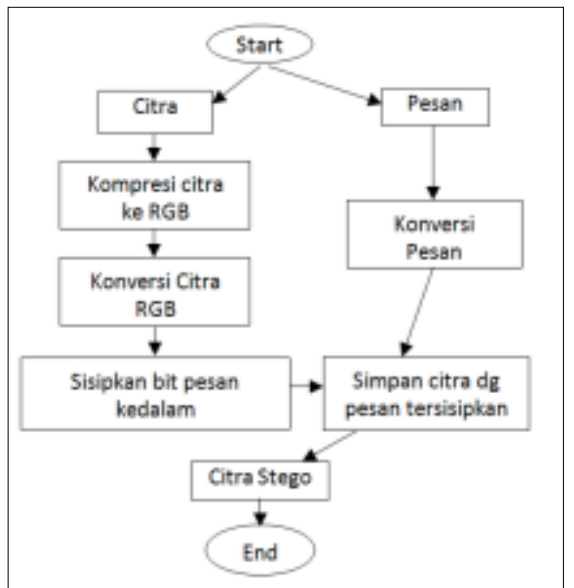

Gambar 3. Skema Algoritma LSB (Encoding)

Setelah itu akan dilakukan pengambilan data citra stego (citra yang sudah tersisipi) kemudian melakukan proses deteksi tepi sobel sebagai pengamanan citra. Gambar 4 dibawah ini merupakan flowchart algoritma deteksi tepi sobel[10]:

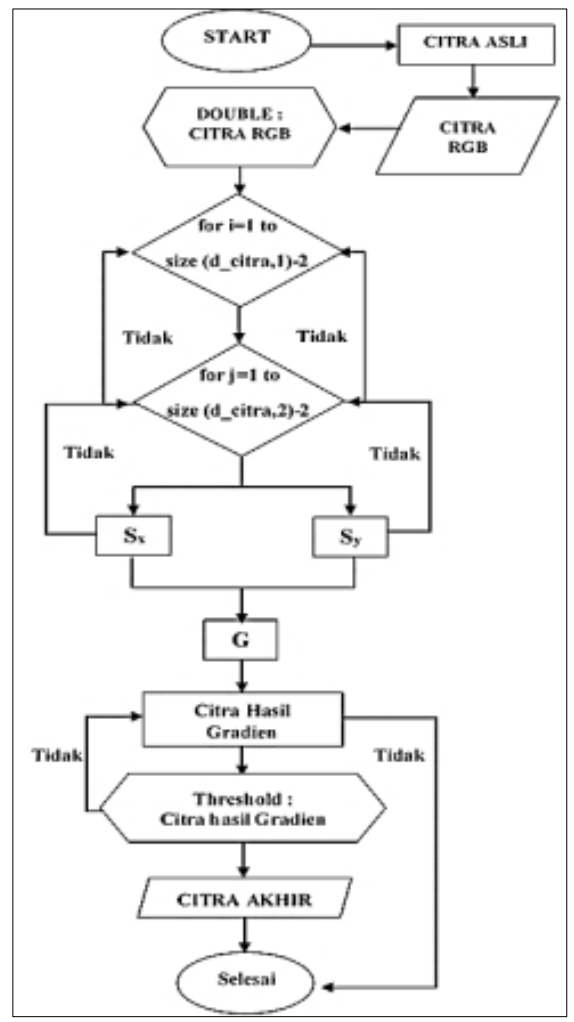

Gambar 4. Skema Algoritma Sobel 


\section{HASIL DAN PEMBAHASAN}

Citra yang digunakan dalam penelitian ini adalah 9 buah citra 8-bit dengan format *.bmp. Citra cover bertipe warna RGB. Citra cover dipilih dari jumlah keypoint yang lebih banyak daripada jumlah bit biner pada pesan agar semua bit biner pesan dapat disisipkan kedalam citra cover.

\section{Enkripsi teks dengan AES}

Berdasarkan algoritma pada gambar 1 diatas, proses pengenkripan teks dengan tulisan "Nomor : 031/IT/V" dan kunci "insistem" diproses menggunakan AES, plaintext yang berisi teks dan kunci dilakukan enkripsi untuk mendapatkan simbol ciphertext seperti disajikan dalam tabel 1 dibawah ini :

Tabel 1. Enkripsi Plainteks dan Kunci Menjadi Ciphertext

\begin{tabular}{|c|c|c|c|c|c|c|c|c|c|}
\hline \multirow[t]{2}{*}{ No } & \multicolumn{3}{|c|}{ Plainteks } & \multicolumn{3}{|c|}{ Kunci } & \multicolumn{3}{|c|}{ Chiperteks } \\
\hline & Simbol & ASCII & Biner & Simbol & ASCII & Biner & ASCII & Biner & Simbol \\
\hline 1 & $\mathrm{~N}$ & $4 \mathrm{E}$ & 01001110 & $\mathrm{i}$ & 69 & 01101001 & 93 & 10010011 & ô \\
\hline 2 & o & $6 \mathrm{~F}$ & 01101111 & $\mathrm{n}$ & $6 \mathrm{E}$ & 01101001 & 97 & 10010111 & ù \\
\hline 3 & $\mathrm{~m}$ & $6 \mathrm{D}$ & 01101101 & s & 73 & 01110011 & $\mathrm{AF}$ & 10101111 & > \\
\hline 4 & o & $6 \mathrm{~F}$ & 01101111 & $\mathrm{i}$ & 69 & 01101001 & DB & 11011011 & - \\
\hline 5 & $\mathrm{r}$ & 72 & 01110010 & $\mathrm{~s}$ & 73 & 01110011 & $\mathrm{AC}$ & 10101100 & $1 / 4$ \\
\hline 6 & (spasi) & 20 & 00100000 & $\mathrm{t}$ & 74 & 01110100 & EB & 11101011 & Ü \\
\hline 7 & $:$ & $3 \mathrm{~A}$ & 00111010 & $\mathrm{e}$ & 65 & 01101001 & 16 & 00011001 & DLE \\
\hline 8 & (spasi) & 20 & 00100000 & $\mathrm{~m}$ & $6 \mathrm{D}$ & 01101001 & D3 & 11010011 & Ё \\
\hline 9 & 0 & 30 & 00110000 & & & 00000000 & 56 & 01010110 & V \\
\hline 10 & 3 & 33 & 00110011 & & & 00000000 & 20 & 00100000 & DC4 \\
\hline 11 & 1 & 31 & 00110001 & & & 00000000 & $\mathrm{C} 2$ & 11000010 & - \\
\hline 12 & I & $2 \mathrm{~F}$ & 00101111 & & & 00000000 & $8 \mathrm{~A}$ & 10001010 & $\dot{\mathrm{e}}$ \\
\hline 13 & I & 49 & 01001001 & & & 00000000 & 47 & 01000111 & G \\
\hline 14 & $\mathrm{~T}$ & 54 & 01010100 & & & 00000000 & 82 & 10000010 & $\hat{\mathrm{e}}$ \\
\hline 15 & I & $2 \mathrm{~F}$ & 00101111 & & & 00000000 & $6 \mathrm{D}$ & 01101110 & M \\
\hline 16 & V & 56 & 01010110 & & & 00000000 & 17 & 00010111 & DC1 \\
\hline
\end{tabular}

Selanjutnya berdasarkan teknik seperti diatas telah dilakukan eksperimen terhadap 6 file dokumen dengan pasangan kuncinya seperti disajikan tabel 2 berikut :

\begin{tabular}{ccc}
\multicolumn{3}{c}{ Tabel 2. Data Eksperimen Enkripsi Dokumen } \\
\hline Dokumen Asli & UkuranDokumen & Kunci \\
\hline dok_1.docx & $12,2 \mathrm{~KB}$ & infomemo \\
dok_2.docx & $13 \mathrm{~KB}$ & inacara \\
dok_3.docx & $12 \mathrm{~KB}$ & inperbaik \\
dok_4.docx & $14,4 \mathrm{~KB}$ & inkonsum \\
dok_5.docx & $12,7 \mathrm{~KB}$ & Insistem \\
\hline
\end{tabular}




\begin{tabular}{lll}
\hline dok_6.docx & $11,6 \mathrm{~KB}$ & Infomemo \\
\hline
\end{tabular}

Hasil dari eksperimen terhadap dokumen pada tabel 2, disajikan pada tabel 3 berikut dibawah ini, dalam bentuk waktu proses dan hasil entropy (semakin mendekati uint8 maka tingkat keacakannya semakin rumit) :

Tabel 3. Durasi Proses Enkripsi dan Entropi Hasil Eksperimen

\begin{tabular}{ccc}
\hline DokumenAsli & Durasi (sec) & Entropy \\
\hline dok_1.docx & 38,073088 & 7,8418 \\
dok_2.docx & 38,669243 & 7,8598 \\
dok_3.docx & 36,826473 & 7,8282 \\
dok_4.docx & 42,757815 & 7,8838 \\
dok_5.docx & 33,649265 & 7,8527 \\
dok_6.docx & 32,61005 & 7,8286 \\
\hline ¿ Rata - rata & 37,09765583 & 7,8491 \\
\hline
\end{tabular}

Didapatkan rata-rata proses enkripsi tiap dokumen sebesar 37.1 detik dengan entropi sebesar 7.8, artinya semakin besar nilai entropi yang mendekati nilai 8 bit integer semakin rumit dan tinggi nilai acaknya.

\section{Penentuan Koordinat dengan Deteksi Tepi Sobel}

Sementara citra yang akan disisipi dokumen akan ditentukan koordinatnya dengan deteksi sobel, citra tersebut dari RGB diubah menjadi grayscale terlebih dahulu, karena deteksi tepi ini mengambil nilai kontras warna background dan foreground. Setelah itu citra grayscale tersebut dideteksi tepinya dengan tresholding sebesar 80 agar tepi lebih jelas. Kemudian hasil dari deteksi yang berupa koordinat tepi yang berfungsi untuk menyisipan teks didalam citra.

Gambar 5 dibawah ini merupakan contoh output dari hasil deteksi tepi sobel dengan hasil deteksi tepi sobel ditambah dengan nilai tresholding :

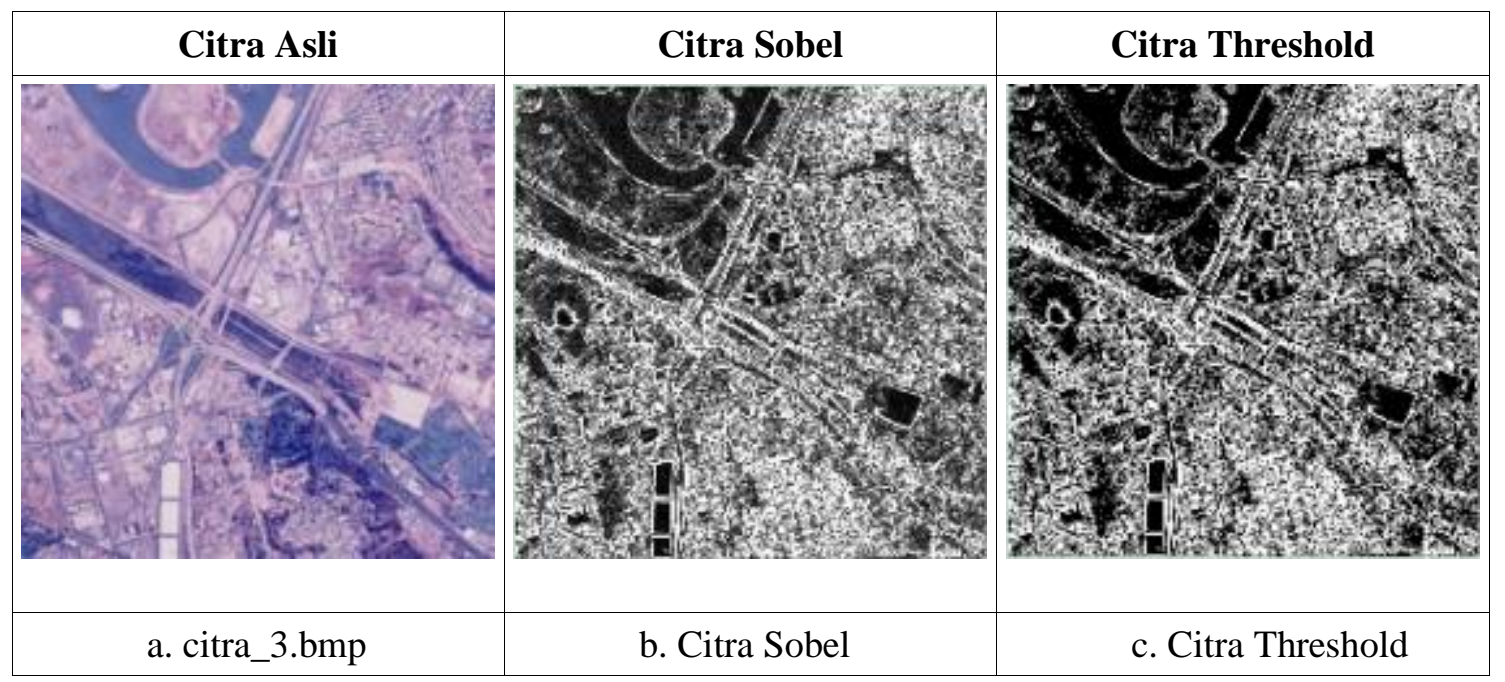

Gambar 5. Citra Deteksi Sobel

Koordinat pada hasil citra deteksi tepi sobel dengan nilai treshold $=80$ disimpan sebagai koordinat untuk penampung dalam proses penyisipan teks dokumen. Pada tabel 4 berikut ini merupakan koordinat dari "citra_3.bmp" untuk penampung teks : 
Tabel 4 : Koordinat dari Citra Sobel Untuk Penampung Teks

\begin{tabular}{cccccc}
\hline Iterasi & $\mathrm{X}$ & $\mathrm{Y}$ & Iterasi & $\mathrm{X}$ & $\mathrm{Y}$ \\
\hline 1 & 2 & 393 & 11 & 2 & 405 \\
2 & 2 & 394 & 12 & 2 & 406 \\
3 & 2 & 395 & 13 & 2 & 409 \\
4 & 2 & 396 & 14 & 2 & 410 \\
5 & 2 & 397 & 15 & 2 & 411 \\
6 & 2 & 398 & 16 & 2 & 414 \\
7 & 2 & 399 & 17 & 2 & 415 \\
8 & 2 & 400 & 18 & 2 & 416 \\
9 & 2 & 401 & $\ldots$ & $\ldots$ & $\ldots$ \\
10 & 2 & 402 & 47.364 & 511 & 511 \\
\hline
\end{tabular}

Setelah itu dilakukan proses LSB, dengan menggunakan koordinat dari hasil proses deteksi tepi sobel diatas. Setelah mendapatkan koordinatnya kemudian proses LSB ini melakukan penyisipan ciphertext dari hasil proses pengenkripan dengan metode AES diatas. Berikut ini merupakan langkah - langkah dalam penyisipan teks ke dalam citra, berdasarkan koordinat dari citra hasil deteksi sobel dan ciphertext hasil dari proses AES yang akan disisipkan dalam citra, kemudian dilakukan proses steganografi dengan menggunakan algoritma LSB, dan akan menghasilkan citra stego, untuk mengetahui perbandingan antara citra asli dan citra stego bisa dilihat dari nilai MSE dan PSNR, selain itu juga bisa dilihat melalui histogram. Sehingga citra berubah menjadi seperti tabel 5 dibawah ini.

Tabel 5 : Hasil Proses Steganografi

\begin{tabular}{ccccccc}
\hline Iterasi & $\mathrm{X}$ & $\mathrm{Y}$ & RGB & Citra Cover & Pesan & Citra Stego \\
\hline 1 & 2 & 5 & 3 & 159 & 1 & 159 \\
2 & 2 & 10 & 3 & 159 & 0 & 159 \\
3 & 2 & 11 & 3 & 181 & 0 & 181 \\
4 & 2 & 24 & 3 & 161 & 1 & 161 \\
5 & 2 & 25 & 3 & 181 & 0 & 181 \\
6 & 2 & 26 & 3 & 194 & 0 & 194 \\
7 & 2 & 27 & 3 & 203 & 1 & 203 \\
8 & 2 & 32 & 3 & 165 & 1 & 165 \\
9 & 2 & 33 & 3 & 185 & 1 & 185 \\
128 & 2 & 454 & 3 & 189 & 1 & 189 \\
\hline
\end{tabular}

Berikut histogram antara citra cover dan citra stego, seperti tabel 6 berikut dibawah ini: 
Tabel 6. Perbandingan Citra Cover dan Stego

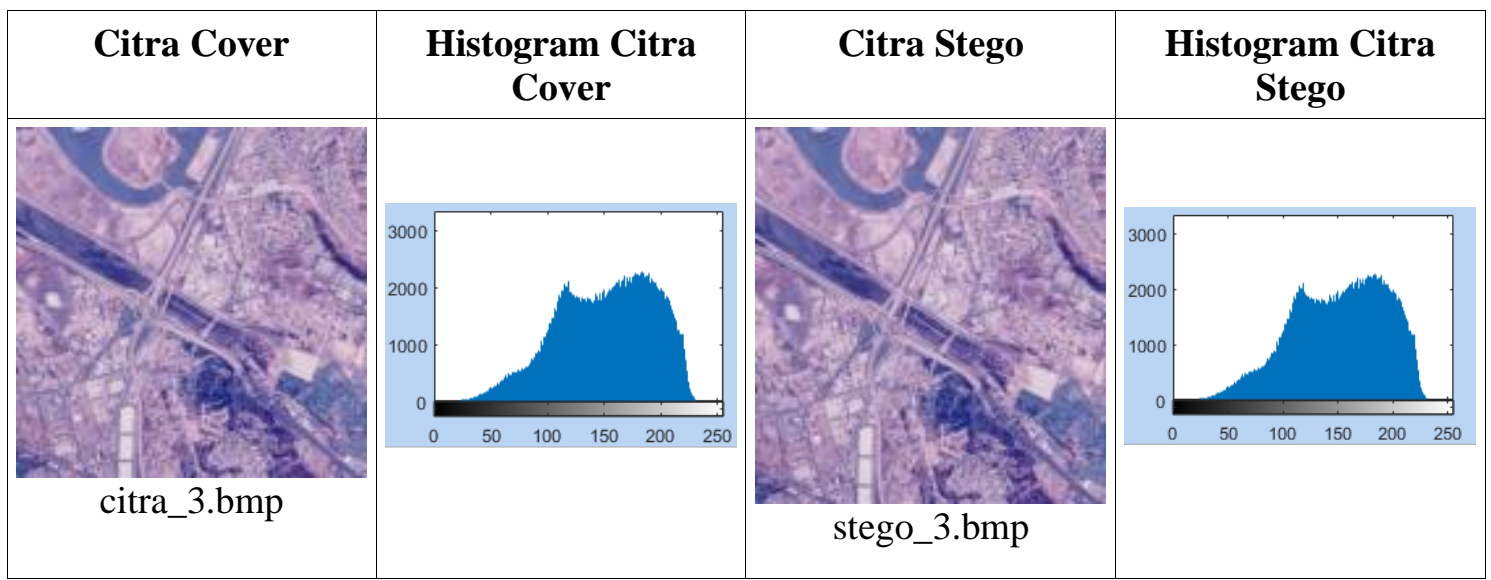

Terlihat histogram hasil perbandingan citra cover sebelum dan sesudah di stego tidak berubah banyak, hal ini menunjukkan bahwa algoritma berhasil melakukan stego tanpa mengalami degradasi yang besar berdasarkan pengamatan visual mata manusia normal, seperti secara jelas disajikan dalam tabel 7 dibawah ini.

Tabel 7 : Hasil Perbandingan Histogram Citra Cover dan Citra Stego

\begin{tabular}{|c|c|c|c|}
\hline $\begin{array}{l}\text { Gradasi } \\
\text { Warna }\end{array}$ & $\begin{array}{c}\text { FrekuensiGradasi } \\
\text { Warna Citra } \\
\text { Cover }\end{array}$ & $\begin{array}{c}\text { FrekuensiGradasi } \\
\text { Warna Citra } \\
\text { Stego }\end{array}$ & $\begin{array}{l}\text { Hasil SelisihFrekuensi } \\
\text { GradiasiWarna }\end{array}$ \\
\hline 1 & 0 & 0 & 0 \\
\hline 2 & 0 & 0 & 0 \\
\hline 3 & 0 & 0 & 0 \\
\hline 4 & 0 & 0 & 0 \\
\hline 5 & 0 & 0 & 0 \\
\hline \multicolumn{4}{|c|}{$\ldots$} \\
\hline 221 & 899 & 900 & 1 \\
\hline 222 & 885 & 880 & 4 \\
\hline 223 & 886 & 890 & 5 \\
\hline \multicolumn{4}{|c|}{$\ldots$} \\
\hline 254 & 0 & 0 & 0 \\
\hline 255 & 0 & 0 & 0 \\
\hline 256 & 0 & 0 & 0 \\
\hline
\end{tabular}

Tabel 7 hanya menampilkan hasil proses yang mengalami perubahan besar antara citra cover dan stego yaitu pada warna 221, 222 dan 223 dimana terdapat perbedaan 1, 4 dan 5 yang artinya hanya kecil sekali perubahan yang diakibatkan penyisipan pada citra cover ke citra stego. Selain itu juga disajikan pada tabel 8 dan 9, Selain hasil selisih frekuensi gradian warna, ada beberapa range yang dapat diperoleh dari perbandingan pada histogram citra cover dan citra stegodiantaranya merupakan hasil perbandingan histogram dari citra cover dan citra stego pada layer Blue: 
Tabel 8. Perbandingan Histogram pada layer Blue

\begin{tabular}{lll}
\hline \multicolumn{1}{c}{ Range } & \multicolumn{1}{c}{ Citra Cover } & \multicolumn{1}{c}{ Citra Stego } \\
\hline Gradian Warna & $0-255$ & $0-255$ \\
Mean & 181,72 & 181,72 \\
Median & 183 & 183 \\
StandarDeviasi & 24,53 & 24,54 \\
Pixels & 262144 & 262144 \\
Percent & 100 & 100 \\
\hline
\end{tabular}

Terlihat bahwa terdapat perbedaan nilai standar deviasi dengan selisih sangat kecil yaitu 0.01, dimananilaibias ini memastikan sangat kecil perbedaan yang ditemukan, sehingga dapat dikatakan bahwa tidak terjadi perubahan yang signifikan antara citra cover dan stego. Juga pada tabel 8, merupakan waktu dalam pemrosesan penyisipan teks dokumen dengan menggunakan LSB :

Tabel 9. Durasi Proses Penyisipan Teks Dengan LSB

\begin{tabular}{ll}
\hline Citra Cover & Durasi LSB $(\mathrm{sec})$ \\
\hline citra_1.bmp & Gagal \\
citra_2.bmp & Gagal \\
citra_3.bmp & 0,352543 \\
citra_4.bmp & 0,542407 \\
citra_5.bmp & 0,379739 \\
citra_6.bmp & 0,335288 \\
\hline I Rata-rata & $\mathbf{0 , 4 0 2 4 9 4 3}$ \\
\hline
\end{tabular}

Terdapat 2 kegagalan pengukuran disebabkan tingginya nilai randon dan putaran yang dilakukan algoritma, namun rata-rata durasi berada pada kisaran 0.4 detik, yang dinilai cukup cepat dalam mengerjakan data tersebut. Dan terakhir hasil evaluasi algoritma dengan mengukur PSNR dan MSE pada model terpilih disajikan pada tabel 10 berikut dibawah ini.

Tabel 10. Evaluasi MSE dan PSNR Pada Model

\begin{tabular}{cccc}
\hline Citra Asli & Citra Stego & MSE & PNSR \\
\hline & $\begin{array}{c}\text { Error. } \\
\text { Karena byte citralebih } \\
\text { kecildibanding byte } \\
\text { dokumennya }\end{array}$ & ERROR & ERROR \\
& & & \\
& & & \\
\hline
\end{tabular}




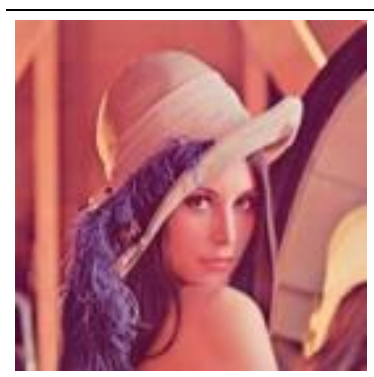

Error.

Karena byte citralebih kecildibanding byte

ERROR

ERROR dokumennya

citra_2.bmp (256 x 256)
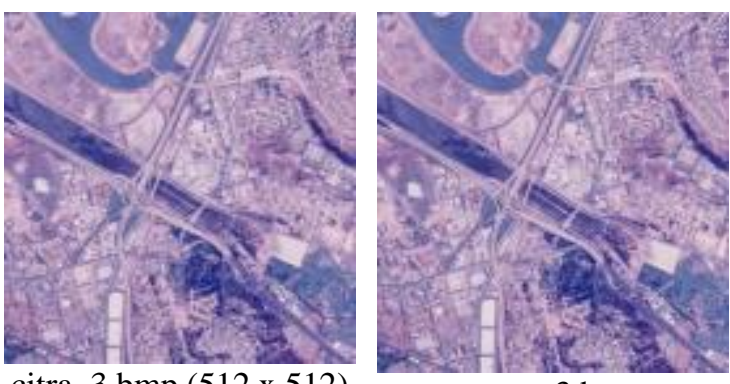

stego_3.bmp
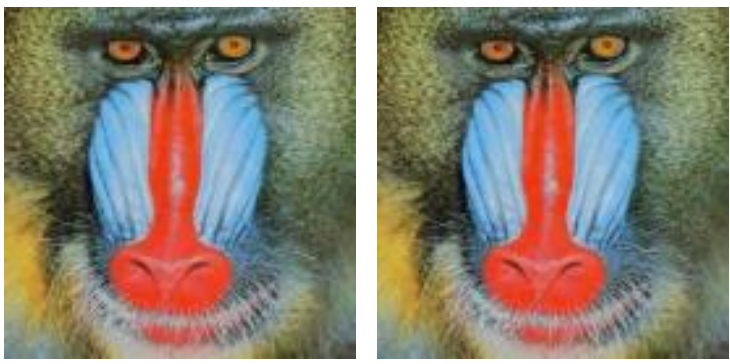

stego_4.bmp

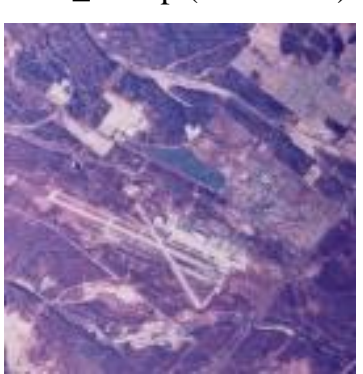

citra_5.bmp

(1024 x 1024)

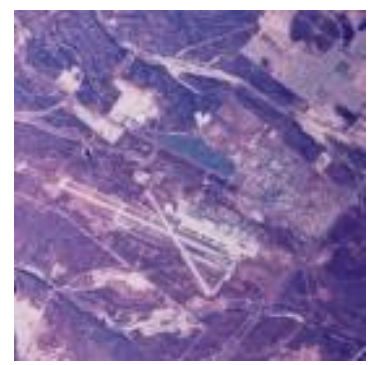

0,0628

60,1498

0,0753

59,3649

stego_5.bmp
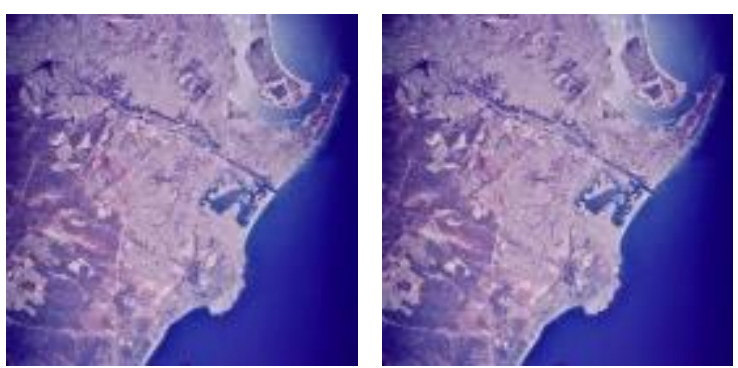

0,0167

65,9160

stego_6.bmp

citra_6.bmp

(1024 x 1024)

$\Sigma$ Rata- rata

0,0425

62,9392

Dari tabel 10 dapat dilihat bahwa hasil penyisipan teks ke citra mendapatkan rata-rata MSE sebesar 0,03835 dan rata-rata hasil PSNR sebesar 63,2871. Dan untuk pada "citra _1.bmp" 
dan "citra_2.bmp" tidak dapat melakukan proses penyisipan dikarenakan besar bit pada citra lebih kecil dibanding besar bit dokumennya.

\section{KESIMPULAN}

Berdasarkan hasil penelitian maka dalam disimpulkan sementara, bahwa hasil rata-rata durasi sebesar 37,0976 detik pada pemrosesan algoritma AES sehingga dapat disimpulkan bahwa kinerja algoritma AES bekerja dengan cukup cepat saat melakukan enkripsi pada teks dokumen penting. Dan dari hasil pemrosesan AES pada size dokumen 14,4 KB memerlukan durasi cukup besar hingga mencapai 42,7578 detik dibanding dokumen lainnya, hal ini disimpulkan bahwa ukuran dokumen sangat mempengerahui kecepatan dalam proses enkripsi.

Hasil durasi saat proses LSB untuk penyisipan teks dalam citra mencapai rata-rata sebesar 0,4024943 detik, selain dengan menggunakan koordinat pada citra hasil deteksi tepi sobel hasilnya bukan hanya bergantung besar kecilnya dimensi namun juga dilihat dari kompleksitas pada objek dalam citra. Dan pada dimensi 256 × 256 tidak bisa melakukan proses LSB, dikarenakan besar byte pada dokumen lebih besar dibanding besar byte pada citra. Hasil kualitas citra stego dalam proses penyisipan teks dokumen setelah dilakukan pengujian terhadap nilai PSNR dan MSE hasil rata-ratanya cukup tinggi yaitu MSE sebesar 0,0425 dan PSNR sebesar 62,9392.

Kompleksitas pada citra juga mempengaruhi hasil MSE dan PSNR, semakin rumit hasil deteksi tepi sobel maka nilai MSE dan PSNR juga semakin besar. Hasil histogram antara citra cover dengan citra stego juga tidak terlihat perubahan yang signifikan, dapat dibuktikan dengan hasil selisih frekuensi gradian warna pada tabel 4.12, gradian warna 221 selisih 1, 222 selisih 5, dan 223 selisih 4. Selain itu, standar deviasi layer blue pada citra cover dan citra stego selisih 0,01 .

\section{SARAN}

Kedepan disarankan untuk menerapkan citra dengan dimensi lebih besar dan kedalaman bit yang lebih dalam dengan harapan dapat mengetahui perbandingan pada hasil proses LSB. Memberi parameter tresholding dengan nilai lebih dari 80 hal ini bertujuan untuk mengetahui pengaruh dari perbandingan hasil MSE dan PSNR.

\section{DAFTAR PUSTAKA}

[1] WIC, "Report on World Internet Development 2017," p. 35, 2017.

[2] M. Kumar, "Don' t Fall For This Dangerously Convincing Ongoing Phishing Attack," pp. $0-2,2017$.

[3] D. Kominfo, “LaporanTahunan KOMINFO 2016,” Jakarta.

[4] Undang-Undang Republik Indonesia Nomor 8 Tahun 1997 Tentang Dokumen Perusahaan , [online] http://www.anri.go.id/assets/download/23UU-Nomor-8-Tahun-1997-TentangDokumen-Perusahaan.pdf [diakses tanggal 06 Juni 2019]

[5] Ahmed Khalid and S. D. Rihan, "A Performance Comparison of Encryption A Performance Comparison of Encryption Algorithms AES and DES," Int. J. Eng. Res. Technol., vol. 4, no. November, pp. 151-154, 2017.

[6] S. Chandran and K. Bhattacharyya, "Performance analysis of LSB, DCT, and DWT for digital watermarking application using steganography," Int. Conf. Electr. Electron. Signals, Commun. Optim. EESCO 2015, no. September, 2015. 
[7] S. Sarkar, "Comparison of various Edge Detection Techniques for maximum data hiding using LSB Algorithm," Int. J. Comput. Sci. Inf. Technol., vol. 5, no. 3, pp. 4722-4727, 2014.

[8] Nurhayati and S. S. Ahmad, "Steganography for inserting message on digital image using least significant bit and AES cryptographic algorithm," Proc. 2016 4th Int. Conf. Cyber IT Serv. Manag. CITSM 2016, 2016.

[9] T. A. Wijaya, "DokumenKaryallmiah | Skripsi | Prodi Teknik Informatika - S1 | FIK | UDINUS | 2016," Fik, vol. 1, no. 1, pp. 1-2, 2016.

[10] N. Jain, S. Meshram, and S. Dubey, "Image Steganography Using LSB and Edge Detection Technique," Int. J. Soft Comput. Eng., vol. 2, no. 3, pp. 217-222, 2012. 